\title{
Effect of postictal process in motor deficit and monoaminergic concentration in hippocampus, cerebellum, and cortex
}

\author{
Alberto Avila-Luna, ${ }^{1}$ Antonio Bueno-Nava, ${ }^{1}$ José Luis Cortes-Altamirano, ${ }^{1,2}$ Samuel Reyes-Long ${ }^{1,3}$ Cindy Bandala, ${ }^{1,3}$ \\ Alfonso Alfaro-Rodríguez
}

Departamento de Neurociencias, Instituto Nacional de Rehabilitación Luis Guillermo Ibarra Ibarra, Ciudad de México, México.

2 Departamento de Quiropráctica, Universidad Estatal del Valle de Ecatepec de Morelos, Estado de México, México.

${ }^{3}$ Escuela Superior de Medicina, Instituto Politécnico Nacional, Ciudad de México, México.

\section{Correspondence:}

Alfonso Alfaro-Rodríguez

División de Neurociencias-Neurofarmacología. Instituto Nacional de Rehabilitación.

Calz. México-Xochimilco 289

Col. Arenal de Guadalupe,

Alcaldía Tlalpan, C.P. 42389 ,

Ciudad de México México.

Phone: (55) 5999 - 1000 ext. 19303

Email: alfa1360@yahoo.com.mx

Received: 10 August 2018

Accepted: 14 August 2019

Citation:

Avila-Luna, A., Bueno-Nava, A.

Cortes-Altamirano, J. L., Reyes-Long

S., Bandala, C., \& Alfaro-Rodríguez,

A. (2019). Effect of postictal process

in motor deficit and monoaminergic concentration in hippocampus, cerebellum, and cortex. Salud Mental, $42(5), 251-256$

DOI: $10.17711 /$ SM.0185-3325.2019.032

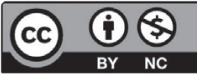

\begin{abstract}
Introduction. Systemic administration of pentylenetetrazole (PTZ) causes brain damage (BD), and triggers a series of morphological and neurochemical changes, which in turn bring about behavioral, cognitive, and motor deficits. Serotonin (5-HT), dopamine (DA), and noradrenaline (NA) levels are controlled by various brain structures and these levels are related to motor activity; however, the concentration of these neurotransmitters during the postictal process remains unknown. Objective. We investigated the concentration of 5-HT, NA and DA in the hippocampus, cerebellum, and cortex on motor deficit during the postictal stage. Method. Eighteen male Wistar rats ( $300 \mathrm{~g})$ assigned to two groups: control $(n=9$, saline solution) and experimental $(n=9, \mathrm{PTZ})$ were used. Myoclonic shakes were counted and motor behavior assessments were recorded during three hours post PTZ injection $(90 \mathrm{mg} / \mathrm{kg})$. The cortex, cerebellum, and hippocampus of each rat were dissected to determine the $5-\mathrm{HT}, \mathrm{DA}$, and NA concentration by high performance liquid chromatography. Results. PTZ induced a significant increase in total 5-HT and DA levels in the hippocampus and cortex; in the cerebellum there was a significant increase in the concentration of $5-\mathrm{HT}$ and NA. The presence of myoclonic shakes as well as a marked motor deficit in the experimental group were significantly different in comparison to the control. Discussion and conclusion. 5-HT modifies the concentration of other monoamines directly involved in motor aspects such as NA and DA in the hippocampus, cerebellum, and cortex during the postictal process.
\end{abstract}

Keywords: Pentylenetetrazole, serotonin, monoamines, postictal, motor deficit, rat.

\section{RESUMEN}

Introducción. La administración sistémica de pentilentetrazol (PTZ) causa daño cerebral y desencadena una serie de cambios morfológicos y neuroquímicos que a su vez provocan déficits conductuales, cognitivos y motores. Los niveles de serotonina (5-HT), dopamina (DA) y noradrenalina (NA) son modulados por varias estructuras cerebrales y sus concentraciones se relacionan con la actividad motora; sin embargo, se desconoce la concentración de estos neurotransmisores durante el proceso postictal. Objetivo. Evaluar la manera en que la concentración de 5-HT, NA y DA en el hipocampo, el cerebelo y la corteza influye en el déficit motor durante la etapa postictal. Método. Se utilizaron 18 ratas macho Wistar $(300 \mathrm{~g})$, divididas en dos grupos: control ( $n=9$, solución salina) y experimental ( $n=9$, PTZ). Se registraron las sacudidas mioclónicas y se evaluó el comportamiento motor durante tres horas después de la inyección de PTZ $(90 \mathrm{mg} / \mathrm{kg})$. Se extrajeron la corteza, el cerebelo y el hipocampo de cada rata para determinar la concentración de 5-HT, DA y NA mediante cromatografía líquida de alta resolución. Resultados. La administración de PTZ indujo un aumento significativo en los niveles totales de 5-HT y DA en el hipocampo y la corteza; en el cerebelo hubo un aumento significativo en la concentración de 5-HT y NA. Se encontró una diferencia significativa entre el grupo experimental y control con respecto a las sacudidas mioclónicas; asimismo, los animales del grupo experimental mostraron un marcado déficit motor. Discusión y conclusión. La 5-HT modula la concentración de otras monoaminas involucradas directamente en aspectos motores tal como NA y DA en el hipocampo, el cerebelo y la corteza durante el proceso postictal.

Palabras clave: Pentilentetrazol, serotonina, monoaminas, postictal, deficit motor, rata. 


\section{INTRODUCTION}

The systemic administration of pentylenetetrazole (PTZ) has been widely employed as an animal model of epilepsy (Peterson \& Albertson, 1998; Sarkisian, 2001; Meldrum, 2002; Eraković, Župan, Varljen, \& Simonić, 2003; Löscher, 2017). Just like patients with epilepsy, animals that are administered PTZ often exhibit behavioral, cognitive and motor abnormalities that generate seizures per se (Ahmadi, Dufour, Seifritz, Mirnajafi-Zadeh, \& Saab, 2017). PTZ acts as an antagonist of $\mathrm{GABA}_{\mathrm{A}}$ receptors in the central nervous system (Macdonald \& Barker, 1977; Kulkarni \& George, 1995; Huang et al., 2001). Histological changes following PTZ administration are: neuronal death and induction of massive degenerative processes (Franke \& Kittner, 2001; Koyuncuoglu et al., 2017). PTZ induces changes in the activity of monoaminergic systems (Becker, Grecksch, Thiemann, \& Höllt, 2000), reduction in levels of noradrenaline (NA) and dopamine (DA) and increased levels of serotonin (5-HT) have been associated with the development of seizures (Shouse, Staba, Ko, Saquib, \& Farber 2001) and motor disorders (Yonekawa, Kupferberg, \& Woodbury, 1980). Currently, the decrease in DA has been related to motor deficit (Felger \& Treadway, 2017), and 5-HT, DA and NA have been implicated in the control of neuronal excitability in epileptic episodes in animal models (Weinshenker \& Szot, 2002). Electroencephalogram has shown an increase in cortical activity during the postictal stage in patients with epilepsy (Harris, Schevon, \& Bateman, 2017). This period of time comprehends a part of the global phenomenon of epilepsy in particular for the recovery of brain activity and to date it has not been clarified how brain levels of 5-HT, DA, and NA influence motor deficit during postictal stage. The aim of the study is to evaluate the concentration of 5-HT, NA, and DA in the hippocampus, cerebellum and cortex on motor deficit during the postictal stage in an animal model of epilepsy induced by PTZ.

\section{METHOD}

\section{Subjects}

Eighteen male Wistar rats with an average weight of 290$300 \mathrm{~g}$ were used. The animals were housed in a 12:12 h light/dark cycle, with a temperature $\left(22\right.$ serotonin a $\left.-24{ }^{\circ} \mathrm{C}\right)$ and humidity $(49 \%-50 \%)$, and fed regular diet and water ad libitum (Purina Chow commercial). The animals were treated according to the Guide for the Care and Use of Experimental Animals (Institute of Laboratory Animal Resources, Committee on Care, Use of Laboratory Animals, \& National Institutes of Health, 1985). In the same way, we were guided according to the Mexican Official Standard NOM-062-ZOO-1999 (2001).

\section{Procedure}

Once used in behavioral tests for the evaluation of motor function (two motor tests such as the impression of the footprint, which evaluates the gait and the equilibrium bar paradigm, which evaluates motor coordination) for five days, subsequently the animals were randomized into two groups: control ( $n=9$, saline solution $1 \mathrm{ml} / \mathrm{kg}$, subcutaneous administration [s.c.]); experimental ( $n=9$, PTZ $90 \mathrm{mg} / \mathrm{kg}$ s.c.).

\section{Analysis of the motor deficit and gait}

After PTZ injection, the number of myoclonic seizures of each rat was recorded for three hours. Twenty-four hours after PTZ administration, global locomotor activity was assessed by means of the equilibrium bar paradigm test, described previously by Brailowsky, Knight, Blood, and Scabini (1986). The records were performed at 0 (Basal), 1, 2 , and $3 \mathrm{~h}$. As described previously by González-Piña, Bueno-Nava, and Montes (2005) the wood tunnel test was used to assess the nature of gait behaviors of rats. The impression of the footprint (length [L], width [A] and the angle [An]) was analyzed. Records were performed at 0 (Basal), 1, 2, and $3 \mathrm{~h}$.

\section{HPLC-EC analysis of 5-HT, DA, and NA concentration}

Rats $(n=18)$ were decapitated and the hippocampus, cerebellum, and cortex were dissected from 9:00 $\mathrm{h}$ am to 13:00 h pm to eliminate circadian variations. Extraction of brain structures and analysis of 5-HT, DA, and NA were performed according to González-Piña and Paz (1997). Tissue was collected in Teflon tubes, and a solution of .5 $\mathrm{ml}$ of perchloric acid $.4 \mathrm{~N}$ containing $.1 \% \mathrm{w} / \mathrm{v}$ of sodium metabisulfite was added. The tissue was then homogenized and centrifuged at $15,000 \mathrm{rpm}$ for $20 \mathrm{~min}$ in $4^{\circ} \mathrm{C}$. The supernatant was filtered and stored at $-70^{\circ} \mathrm{C}$ for High Performance Liquid Chromatography (HPLC). 5-HT, DA and NA content was analyzed by HPLC (Alltech, HPLC Pump, Model: 626) using a coulometric electrochemical detector (ESA, Model: Coulochem III). Detection conditions were as follows: analytical cell (ESA 5011A) with the potentials $=+350 \mathrm{mV}, \mathrm{E} 1=+200 \mathrm{mV}$ and $\mathrm{E} 2=-200 \mathrm{mV}$. The peaks were sent to a computer with an EZCrom SI (version 3.2.1) program. To determine the concentrations of 5-HT, DA, and NA the chromatograms of the samples were interpolated using chromatograms from five standard samples with known 5-HT, DA, and NA concentrations. An analytical column for catecholamines was used (Alltech, Adsorbosphere Catecholamine, $100 \times 4.6 \mathrm{~mm}, 3 \mu \mathrm{m}$ of particle size). The mobile phase consisted of a phosphate buffer solution $(.1 \mathrm{mM}, \mathrm{pH}$ 3.2) containing (in $\mathrm{mM}$ ) sodium octyl sulfate (.2), EDTA (.1) and methanol $(15 \% \mathrm{v} / \mathrm{v})$. The flow rate was $1.6 \mathrm{ml} / \mathrm{min}$. 


\section{Statistical analysis}

Statistical analysis of 5-HT, DA, and NA measurements was performed with a one-way analysis of variance (ANOVA) and a post hoc Tukey test, and the data of the motor function tests was analyzed using a non-parametric Mann-Whitney's U. In all cases, the differences were considered significant at $p<.05$. The results in the text and figures are expressed as the means \pm S.E.M.

\section{RESULTS}

\section{Effect of PTZ on myoclonic shakes}

Systemic administration of PTZ $(90 \mathrm{mg} / \mathrm{kg}$ ) provoked myoclonic shakes in all animals in the experimental group, which were quantified for three hours. A maximum in the number of shakes was reached in the first hour and then it began to decline reaching almost zero at the end of the recording. When comparing the hours of recording, a significant decrease was found at hour $1(p=.001)$, hour $2(p=.001)$, and hour $3(p=.003)$ (Figure 1).

\section{Assessment of gait}

After the PTZ $(90 \mathrm{mg} / \mathrm{kg}$ ) administration, a significant increase in the percentage of stride length was found when comparing hour $1(p=.0005)$, hour $2(p=.0005)$, and hour $3(p=.001)$ between control and experimental groups a tendency of the data to return to basal conditions was observed. Regarding stride width, significant differences were present between the two groups at hour $1(p=.026)$, hour $2(p=$ $.0019)$, and hour $3(p=.001)$. The highest percentage of increase in stride width was found in hour 2 (Figure 2).

Likewise, there was an increase in the percentage of stride angle when comparing between control and experimental groups at hour $1(p=.0027)$, hour $2(p=.0027)$, and hour $3(p=.0005)$. A tendency to recover the basal values was also present as time elapsed (Figure 3).

\section{Evaluation of motor coordination}

There was a $456 \%$ increase in motor deficit at hour 1 ( $p=$ $.0003) ; 284 \%$ at hour $2(p=.0003)$, and $137 \%$ at hour $3(p$ $=.024)$ when comparing control and experimental groups (Figure 4).

\section{Concentration of 5-HT, DA, and NA}

Table 1 shows the total concentration of 5-HT, DA, and NA in the cortex, cerebellum, and hippocampus of the control and experimental groups. A significant increase of 5-HT ( $p<$ $.05)$ and a highly significant increase of DA $(p<.001)$ were

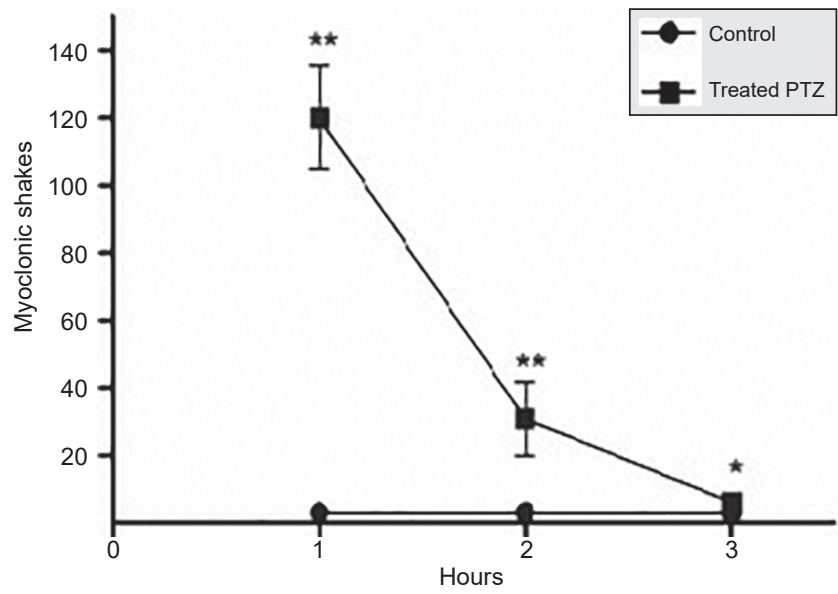

Figure 1. Number of myoclinic shakes of the head of animals in experimental group (PTZ $90 \mathrm{mg} / \mathrm{kg}$ ) and in control group, recorded during three hours. Data are expressed as mean \pm S.E.M. ${ }^{*} p=.003,{ }^{* *} p=.001$.
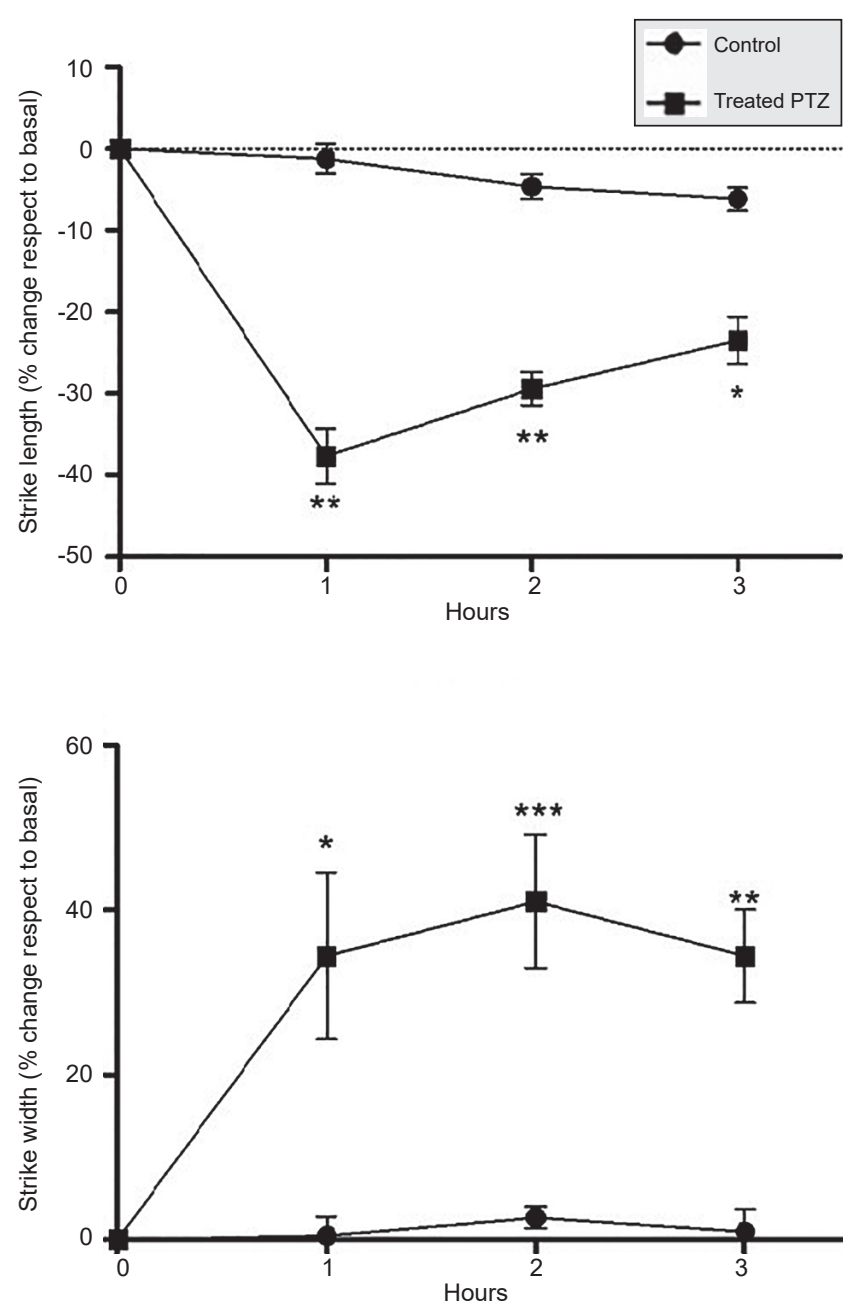

Figure 2. Percentage of change in the stride length and the width of animals in experimental group (PTZ $90 \mathrm{mg} / \mathrm{kg}$ ) and control group, recorded during three hours. Data are expressed as mean \pm S.E.M. ${ }^{*} p=.001,{ }^{* *} p=.0005$. 


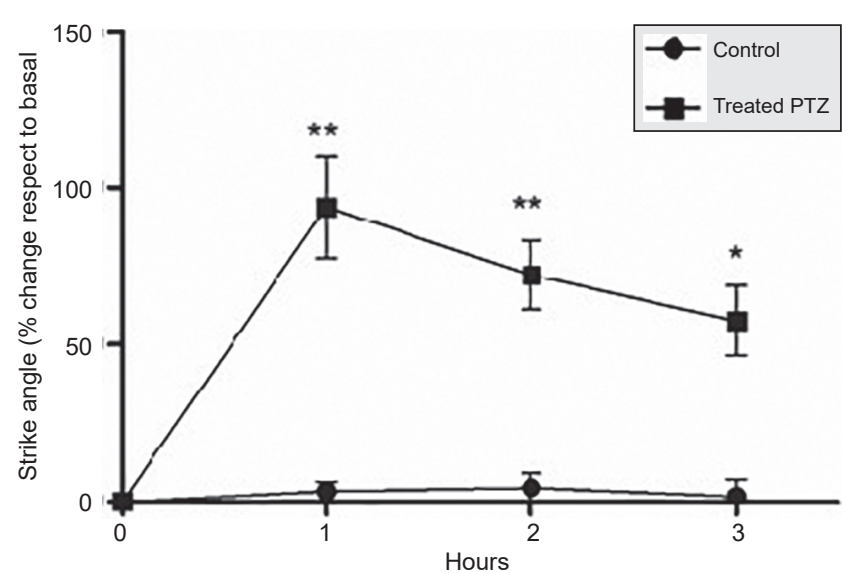

Figure 3. Percentage of change in the stride angle of animals in experimental group (PTZ $90 \mathrm{mg} / \mathrm{kg}$ ) and control group, recorded during three hours. Data are expressed as mean \pm S.E.M. ${ }^{*} p=.0027,{ }^{* *} p=.0005$.

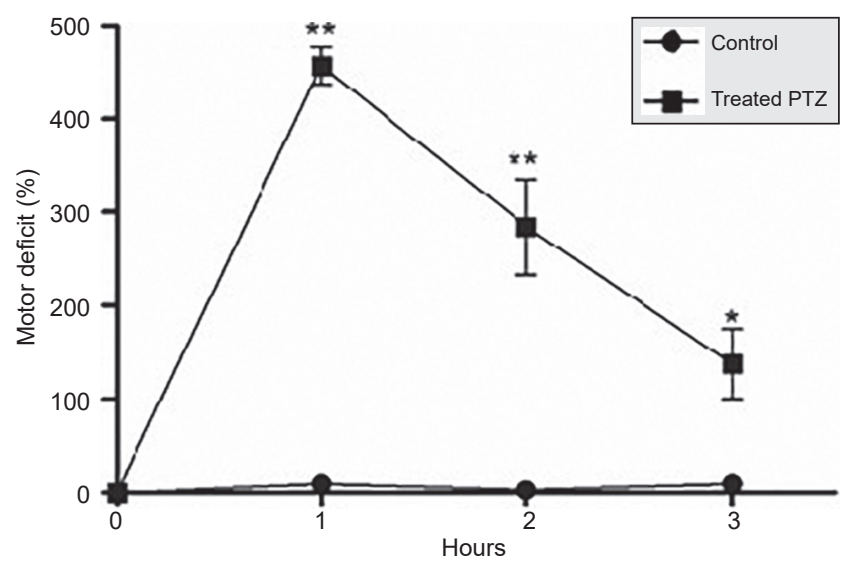

Figure 4. Percentage of change in the stride angle of animals in experimental group (PTZ $90 \mathrm{mg} / \mathrm{kg}$ ) and control group, recorded during three hours. Data are expressed as mean \pm S.E.M. ${ }^{*} p=.0024,{ }^{* *} p=.0003$.

Table 1

Effect of PTZ (90mg/kg), on total levels of serotonin (5-HT), dopamine (DA) and noradrenaline (NA) in the brain of the rat

\begin{tabular}{lccc}
\hline & $5-H T(\mathrm{nmol} / \mathrm{g})$ & $D A(\mathrm{nmol} / \mathrm{g})$ & $N A(\mathrm{nmol} / \mathrm{g})$ \\
\hline Cortex & & & \\
$\quad$ Control & $3.63 \pm .90$ & $64.68 \pm 21.99$ & $207.74 \pm 19.89$ \\
$\quad$ Experimental & $7.32 \pm 1.08^{*}$ & $245.85 \pm 91^{* *}$ & $215.57 \pm 23.75$ \\
Cerebellum & & & \\
$\quad$ Control & $9.32 \pm 1.42$ & $2.38 \pm .34$ & $94.88 \pm 2.67$ \\
$\quad$ Experimental & $15.82 \pm 1.76^{*}$ & $1.58 \pm .22$ & $99.63 \pm 1.68^{*}$ \\
Hippocampus & & & \\
$\quad$ Control & $5.55 \pm 1.21$ & $38.72 \pm 7.80$ & $255.72 \pm 39.03$ \\
Experimental & $23.95 \pm 7.75^{*}$ & $94.05 \pm 37.11^{*}$ & $277.55 \pm 34.07$ \\
\hline
\end{tabular}

Note: Values were expressed as the $\mathrm{M} \pm \mathrm{S}$.E.M. During the statistical analysis a one- way ANOVA was used. The significant differences compared to the control group were ${ }^{*} p<.05,{ }^{* *} p<.001$. present in the cortex comparing control and experimental groups. No significant differences were found in NA.

The concentration of 5-HT in the cerebellum exhibits a statistically significant increase in the experimental group compared to the control $(p<.05)$. The same was observed regarding NA concentration $(p<.05)$; no significant differences in DA concentration were observed between the two groups. In the hippocampus, the concentration of 5-HT and DA significantly increased $(p<.05)$ in the experimental group three hours after subcutaneous administration of PTZ $(90 \mathrm{mg} / \mathrm{kg})$; there were none significant differences between groups in NA concentration.

\section{DISCUSSION AND CONCLUSION}

In animals under an epilepsy model induced by PTZ ( 90 $\mathrm{mg} / \mathrm{kg}$ ), a significant increase was present in total 5-HT levels in hippocampus, cerebellum, and cortex, whereas DA displayed a significant increase in both hippocampus and cortex. As for NA, a significant increase was present in the cerebellum.

On the other hand, there was a decrease in the motor function in the adult rat during the postictal stage. 5-HT projects to almost all brain areas and participates in sensory, behavioral, and motor activity processes (Pérez-García, LiySalmerón, \& Meneses, 2006). Acute administration of PTZ $(90 \mathrm{mg} / \mathrm{kg}$ ) induced an increase of 5-HT at the hippocampus, cerebellum, and cortex levels, which caused an imbalance of the serotonergic system resulting in an aberrant behavior as described by Adamec, Burton, Blundell, Murphy, and Holmes (2006). Our results are consistent with studies conducted by Gholipour, Ghasemi, Riazi, Ghaffarpour, and Dehpour (2010), which describe an increase in serotonergic neurotransmission in the hippocampus after the induction of seizures. Increased levels of 5-HT in the hippocampus, cerebellum, and cortex of PTZ-treated rats could be a compensatory response to neuronal excitability following PTZ-induced brain damage. During the convulsive process produced by the PTZ, not only are glutamatergic and GABAergic systems involved, but also monoaminergic systems (Kalynchuk, 2000). PTZ is a GABA antagonist, which apart from inhibiting excitation in the brain, also modulates the activity of monoaminergic systems (Becker et al., 2000). It has been previously shown that direct lesions on serotonergic neurons can produce a compensatory response such as serotonergic reorganization in the area of the dentate gyrus after damage to the median raphe nucleus (Haring, 1991). On the other hand, the levels of DA in our study were elevated in the hippocampus and the cortex, these results agree with what was proposed by Lee et al. (2015), whose aim was to evaluate the relationship between the dopaminergic and serotoninergic systems in an animal model of Parkinson's disease. They concluded that there was a positive correlation 
between the dopaminergic deficit and the serotonergic deterioration in terms of potential binding. Although different pathologies are evaluated, some relations can be inferred in the particular case of the postictal stage as we can observe an increase in the concentration in both neurotransmitters in the hippocampus and cortex, i.e., a positive correlation to regain homeostasis within the postictal stage. In this study, NA displayed a statistical increase in the cerebellum. This particular area, in contrast to the cerebral cortex and hippocampus, exhibits fewer metabolic changes during epileptic status (Folbergrová, Ingvar, \& Siesjö, 1981); however, high levels of noradrenaline in the brain activate the alpha- 1 autoreceptor in the serotonergic neuron, increasing the rate of triggering and releasing serotonin (Bhagya, Srikumar, Raju, \& Shankaranarayana, 2015).

The acute systemic administration of PTZ caused a marked transient cerebral dysfunction reflected in the motor deficit. The hippocampus has cellular elements that receive inputs and outputs to important areas of pons and cerebral cortex. Newman and Reza (1979) hypothesized that there are relationships between the hippocampus and the cerebellum. The pattern of electrical activity developed by the hippocampus is closely related to the realization of movements that occur during excitation and other behavioral changes. None of the proposals that have been made state that the hippocampus participates in a feedback of muscle activity but emphasizes the possibility of a direct influence on motor control systems (Bueno-Nava et al., 2010). Assuming that the output of the hippocampus can modulate the motor control circuits, it is reasonable to suggest that the hippocampus itself guides the signals of the cerebellum for its normal operations. In turn, the hippocampus is involved in providing the information required for the cerebellum, just as proprioceptive information is used to correct movements in the locomotor system. There are fast and slow connections that operate in both directions. In some morphological studies, it has been shown that PTZ causes loss of neurons in many brain structures. Neuronal necrosis is found in the hippocampus areas $\mathrm{CA} 1, \mathrm{CA} 3$, and in the dentate gyrus regions (Franke \& Kittner 2001). Therefore, it is possible that the alteration in the motor activity is due to a deterioration of the acquisition and/or retention of contextual signals, caused by damage to the hippocampus.

Our results indicate that both the long width and angle of stride increased considerably after administration of PTZ. Presumably, these results were induced by loss of neurons and/or damage in the brain-cerebellum connectivity, in addition to monoaminergic imbalance. Similarly, the balance bar is a test that can qualitatively measure the motor coordination of the rat (Hruska, Kennedy, \& Silbergeld 1979). It has been reported that focal cortical damage in rats induces a temporary motor deficit (Bueno-Nava et al., 2008: Goldstein, 2006; González-Piña et al., 2005). Together, the reciprocal connections that link the hippocampus to the cerebellum and the cortex derive from the participation of neurotransmitters involved in cognitive and motor aspects, such as 5-HT, NA, and DA (Dempesy et al., 1983; Marcinkiewicz, Morcos, \& Chretien, 1989).

The results of the present study revealed that the administration of PTZ significantly increased the motor deficit during the three hours of recording. Data in this study could indicate that the changes in motor behavior observed may be due to the modification in the synthesis and release of the monoamines, caused by altered synaptic regulatory processes, which may occur as a result of neuronal loss, gliosis, or neuronal outbreaks as described by Szyndler et al. (2002). However, the return to basal motor conditions is evident both in motor behavior and in myoclonic shakes after PTZ administration after the second hour, so it can be speculated that mechanisms that lead to a spontaneous recovery of the levels of monoamines may be present, thus reducing the degree of motor deficit. More studies are needed to elucidate the underlying mechanisms of brain recovery after an epileptic seizure. In particular, the specific role of structures such as the rafe dorsal nucleus [5-HT], Locus Coeruleus [NA], and striatum [DA] contributions during the postictal process, in order to develop pharmacological strategies to reduce damage after of the ictal stage in humans. Acute administration of PTZ at a dose of $90 \mathrm{mg} / \mathrm{kg}$ generates a motor deficit and increases the concentration of 5-HT in the hippocampus, cerebellum, and cortex due to the convulsive activity. Presumably, there is an indirect participation between serotonin and motor changes, when acting as a neuromodulator, since 5-HT modifies the concentration of other monoamines directly involved in motor aspects such as NA and DA during the postictal stage.

\section{Funding}

None.

\section{Conflict of interests}

The authors declare they have no conflicts of interest.

\section{REFERENCES}

Adamec, R., Burton, P., Blundell, J., Murphy, D. L., \& Holmes, A. (2006). Vulnerability to mild predator stress in serotonin transporter knockout mice. Behavioural Brain Research, 170(1), 126-140. doi: 10.1016/j.bbr.2006.02.012

Ahmadi, M., Dufour, J. P., Seifritz, E., Mirnajafi-Zadeh, J., \& Saab, B. J. (2017). The PTZ kindling mouse model of epilepsy exhibits exploratory drive deficits and aberrant activity amongst VTA dopamine neurons in both familiar and novel space. Behavioural Brain Research, 330, 1-7. doi: 10.1016/j.bbr.2017.05.025

Becker, A., Grecksch, G., Thiemann, W., \& Höllt, V. (2000). Pentylenetetrazolkindling modulates stimulated dopamine release in the nucleus accumbens of rats. Pharmacology Biochemistry and Behavior, 66(2), 425-428. doi: 10.1016/ S0091-3057(99)00264-6

Bhagya, V., Srikumar, B. N., Raju, T. R., \& Shankaranarayana Rao, B. S. (2015). The selective noradrenergic reuptake inhibitor reboxetine restores spatial learning deficits, biochemical changes, and hippocampal synaptic plasticity in an animal model of depression. Journal of Neuroscience Research, 93(1), 104-120. doi: $10.1002 /$ jnr. 23473 
Brailowsky, S., Knight, R. T., Blood, K., \& Scabini, D. (1986). $\gamma$-Aminobutyric acidinduced potentiation of cortical hemiplegia. Brain Research, 362(2), 322-330. doi: 10.1016/0006-8993(86)90457-9

Bueno-Nava, A., Gonzalez-Pina, R., Alfaro-Rodriguez, A., Nekrassov-Protasova, V., Durand-Rivera, A., Montes, S., \& Ayala-Guerrero, F. (2010). Recovery of motor deficit, cerebellar serotonin and lipid peroxidation levels in the cortex of injured rats. Neurochemical Research, 35(10), 1538-1545. doi: 10.1007/s11064010-0213-4

Bueno-Nava, A., Montes, S., DelaGarza-Montano, P., Alfaro-Rodriguez, A., Ortiz, A., \& Gonzalez-Pina, R. (2008). Reversal of noradrenergic depletion and lipid peroxidation in the pons after brain injury correlates with motor function recovery in rats. Neuroscience Letters, 443(1), 32-36. doi: 10.1016/j. neulet.2008.07.046

Dempesy, C. W., Tootle, D. M., Fontana, C. J., Fitzjarrell, A. T., Garey, R. E., \& Heath, R. G. (1983). Stimulation of the paleocerebellar cortex of the cat: increased rate of synthesis and release of catecholamines at limbic sites. Biological Psychiatry, 18(1), 127-132.

Eraković, V., Župan, G., Varljen, J., \& Simonić, A. (2003). Pentylenetetrazol-induced seizures and kindling: changes in free fatty acids, superoxide dismutase, and glutathione peroxidase activity. Neurochemistry International, 42(2), 173-178. doi: 10.1016/S0197-0186(02)00070-0

Felger, J. C., \& Treadway, M. T. (2017). Inflammation effects on motivation and motor activity: role of dopamine. Neuropsychopharmacology, 42(1), 216-241. doi: $10.1038 / \mathrm{npp} .2016 .143$

Folbergrová, J., Ingvar, M., \& Siesjö, B. K. (1981). Metabolic changes in cerebral cortex, hippocampus, and cerebellum during sustained bicuculline-induced seizures. Journal of Neurochemistry, 37(5), 1228-1238. doi: 10.1111/j.14714159.1981.tb04673.x

Franke, H., \& Kittner, H. (2001). Morphological alterations of neurons and astrocytes and changes in emotional behavior in pentylenetetrazol-kindled rats. Pharmacology Biochemistry and Behavior, 70(2-3), 291-303. doi: 10.1016/ S0091-3057(01)00612-8

Gholipour, T., Ghasemi, M., Riazi, K., Ghaffarpour, M., \& Dehpour, A. R. (2010). Seizure susceptibility alteration through 5 -HT3 receptor: modulation by nitric oxide. Seizure, 19(1), 17-22. doi: 10.1016/j.seizure.2009.10.006

Goldstein, L. B. (2006). Neurotransmitters and motor activity: effects on functional recovery after brain injury. NeuroRx, 3(4), 451-457. doi: 10.1016/j. nurx.2006.07.010

González-Piña, R., \& Paz, C. (1997). Brain monoamine changes in rats after short periods of ozone exposure. Neurochemical Research, 22(1), 63-66. doi: 10.1023/A:1027329405112

González-Piña, R., Bueno-Nava, A., Montes, S., Alfaro-Rodriguez, A., GonzalezMaciel, A., Reynoso-Robles, R., \& Ayala-Guerrero, F. (2005). Pontine norepinephrine content after motor cortical ablation in rats. Proceedings of the Western Pharmacology Society, 48,73-76.

Haring, J. H. (1991). Reorganization of the area dentata serotoninergic plexus after lesions of the median raphe nucleus. Journal of Comparative Neurology, 306(4), 576-584. doi: 10.1002/cne.903060404

Harris, D., Schevon, C., \& Bateman, L. (2017). Postictal Clinical Features of Focal Dyscognitive Seizures (P4. 074). Neurology, 88(16 Supplement), P4-074. ISSN:1526-632X

Hruska, R. E., Kennedy, S., \& Silbergeld, E. K. (1979). Quantitative aspects of normal locomotion in rats. Life Sciences, 25(2), 171-179. doi: 10.1016/00243205(79)90389-8

Huang, R. Q., Bell-Horner, C. L., Dibas, M. I., Covey, D. F., Drewe, J. A., \& Dillon, G. H. (2001). Pentylenetetrazole-induced inhibition of recombinant $\gamma$-aminobutyric acid type A (GABAA) receptors: mechanism and site of action. Journal of Pharmacology and Experimental Therapeutics, 298(3), 986-995.

Institute of Laboratory Animal Resources (US). Committee on Care, Use of Laboratory Animals, \& National Institutes of Health (US). Division of Research
Resources. (1985). Guide for the care and use of laboratory animals. National Academies.

Kalynchuk, L. E. (2000). Long-term amygdala kindling in rats as a model for the study of interictal emotionality in temporal lobe epilepsy. Neuroscience \& Biobehavioral Reviews, 24(7), 691-704. doi: 10.1016/S0149-7634(00)00031-2

Koyuncuoglu, T., Vızdıklar, C., Üren, D., Yılmaz, H., Yıldırım, Ç., Atal, S. S., ...Yeğen, B. Ç. (2017). Obestatin improves oxidative brain damage and memory dysfunction in rats induced with an epileptic seizure. Peptides, 90, 37-47. doi: 10.1016/j.peptides.2017.02.005

Kulkarni, S. K., \& George, B. (1995). Pentylenetetrazol-induced kindling in animals: protective effect of BR-16A. Indian Journal of Experimental Biology, 33(6), 424-427.

Lee, M., Ryu, Y. H., Cho, W. G., Kang, Y. W., Lee, S. J., Jeon, T. J., ... Choi, T. H. (2015). Relationship between dopamine deficit and the expression of depressive behavior resulted from alteration of serotonin system. Synapse, 69(9), 453-460. doi: doi.org/10.1002/syn.21834

Löscher, W. (2017). Animal models of seizures and epilepsy: past, present, and future role for the discovery of antiseizure drugs. Neurochemical Research, 42(7), 1873-1888. doi: 10.1007/s11064-017-2222-z

MacDonald, R. L., \& Barker, J. L. (1977). Pentylenetetrazol and penicillin are selective antagonists of GABA-mediated post-synaptic inhibition in cultured mammalian neurones. Nature, 267(5613), 720-721. doi: 10.1038/267720a0

Marcinkiewicz, M., Morcos, R., \& Chretien, M. C. N. S. (1989). CNS connections with the median raphe nucleus: Retrograde tracing with WGA-apoHRP-gold complex in the rat. Journal of Comparative Neurology, 289(1), 11-35. doi: 10.1002/cne.902890103

Meldrum, B. (2002). Do preclinical seizure models preselect certain adverse effects of antiepileptic drugs. Epilepsy Research, 50(1-2), 33-40. doi: 10.1016/S09201211(02)00066-9

Newman, P. P., \& Reza, H. (1979). Functional relationships between the hippocampus and the cerebellum: an electrophysiological study of the cat. The Journal of Physiology, 287(1), 405-426. doi: 10.1113/jphysiol.1979.sp012667

Norma Oficial Mexicana NOM-062-ZOO-1999. (2001). Especificaciones técnicas para la producción, cuidado y uso de los animales de laboratorio. Retrieved from: http://www.gob.mx/cms/uploads/attachment/file/203498/NOM-062ZOO-1999_220801.pdf

Pérez-García, G., Liy-Salmerón, G., \& Meneses, A. (2006). Receptores serotonérgicos y memoria. Revista Mexicana de Análisis de la Conducta, 32(2), 241-269. ISSN: 0185-4534

Peterson, S. L., \& Albertson, T. E. (1998). Neuropharmacology methods in epilepsy research. CRC press. ISBN 13: 978-0-8493-3362-0

Sarkisian, M. R. (2001). Overview of the current animal models for human seizure and epileptic disorders. Epilepsy \& Behavior, 2(3), 201-216. doi: 10.1006/ ebeh.2001.0193

Shouse, M. N., Staba, R. J., Ko, P. Y., Saquib, S. F., \& Farber, P. R. (2001). Monoamines and seizures: microdialysis findings in locus ceruleus and amygdala before and during amygdala kindling. Brain research, 892(1), 176192. doi: 10.1016/S0006-8993(00)03292-3

Szyndler, J., Rok, P., Maciejak, P., Walkowiak, J., Członkowska, A. I., SienkiewiczJarosz, H., ... Kostowski, W. (2002). Effects of pentylenetetrazol-induced kindling of seizures on rat emotional behavior and brain monoaminergic systems. Pharmacology Biochemistry and Behavior, 73(4), 851-861. doi: 10.1016/S0091-3057(02)00912-7

Weinshenker, D., \& Szot, P. (2002). The role of catecholamines in seizure susceptibility: new results using genetically engineered mice. Pharmacology \& Therapeutics, 94(3), 213-233. doi: 10.1016/S0163-7258(02)00218-8

Yonekawa, W. D., Kupferberg, H. J., \& Woodbury, D. M. (1980). Relationship between pentylenetetrazol-induced seizures and brain pentylenetetrazol levels in mice. Journal of Pharmacology and Experimental Therapeutics, 214(3), 589593. 